\title{
Fatal Campylobacter jejuni infection in a patient splenectomised for thalassaemia
}

\author{
N Jackson, M Zaki, A R Rahman, M Nazim, M N Win, S Osman
}

\begin{abstract}
A 35 year old man with a fatal Campylobacter jejuni infection is described. He had $\mathrm{HbE} / \beta^{\circ}$ thalassaemia and had undergone splenectomy nine months previously for hypersplenism; he also had chronic hepatitis $C$ infection. He presented with high grade fever but no gastrointestinal symptoms and rapidly progressed to septicaemic shock and hepatic encephalopathy despite treatment with penicillin, gentamicin, and, later, chloramphenicol and ceftazidime. Only one case of Campylobacter jejuni septicaemia occuring post-splenectomy has been reported previously, also in an iron overloaded thalassaemia patient. Unusual Gram negative bacilli must be covered by the chosen antibiotic regimen when splenectomised thalassaemic patients present with high grade fever.

(f Clin Pathol 1997;50:436-437)
\end{abstract}

Keywords: campylobacter; splenectomy; thalassaemia

The most common and serious infections in splenectomised patients are those due to Streptococcus pneumoniae, Haemophilus influenzae type b and Neisseria meningitidis. ${ }^{1}$ Current recommendations for prophylaxis in splenectomised individuals include routine immunisation against the first two of these organisms, and against the third when the patient is travelling to an endemic area. ${ }^{2}$ However, Gram negative bacilli and protozoal infections have also to be considered, especially in patients with other immune defects. We describe a very unusual case of overwhelming septicaemia due to Campylobacter jejuni in a splenectomised individual with iron overload and chronic liver disease.

Medicine, Hospital

Universiti Sains

Malaysia, 16150 Kota

Bharu, Kelantan,

Malaysia

N Jackson

A R Rahman

$M$ Nazim

$M N$ Win

Department of

Microbiology

$M$ Zaki

S Osman

Correspondence to: Dr Jackson.

e-mail: alison@kb.usm.my

Accepted for publication 26 February 1997 cal markers for hepatitis C. A splenectomy had been done nine months previously for hypersplenism, after which he had remained pale and jaundiced, but he had not required transfusion. Pneumococcal vaccine had not been available but he was taking oral phenoxymethylpenicillin $250 \mathrm{mg}$ twice daily, with good compliance.

On examination at the time of this admission he was deeply jaundiced, his temperature was $40.5^{\circ} \mathrm{C}$ but he was alert. Blood pressure was $120 / 70 \mathrm{~mm} \mathrm{Hg}$ and central nervous system examination was normal. There was evidence of marked derangement of liver function, but renal function was initially normal. Chest $x$ ray showed cardiomegaly and mild pulmonary congestion. HIV antibody test was negative. $\mathrm{He}$ was treated with intravenous benzylpenicillin $4 \mathrm{MU}$ every four hours, and gentamicin $80 \mathrm{mg}$ every eight hours (equivalent to $5.6 \mathrm{mg} / \mathrm{kg}$ / day).

By the second day, his blood pressure was $90 / 50 \mathrm{~mm} \mathrm{Hg}$ and he was drowsy and irritable but with no focal neurological signs or meningism. Chloramphenicol $1 \mathrm{~g}$ every six hours was added against the possiblity of haemophilus meningitis. Later the same day, computed tomography of the brain showed slight effacement of sulci but no mass lesion or meningeal enhancement; an electroencephalogram showed encephalopathic changes; and cerebrospinal fluid examination was normal. No malarial parasites were seen on a blood film. A diagnosis of hepatic encephalopathy was made, and oral neomycin and lactulose were added.

On the third day, he became photophobic with neck stiffness, a positive Kernig's sign, bilateral sustained clonus, and an extensor plantar reflex on the left side. Serum gentamicin concentration was subtherapeutic (pre-dose $0.9 \mathrm{mg} / \mathrm{l}$, one hour post-dose $3.13 \mathrm{mg} / \mathrm{l})$. However, in view of deteriorating renal function (blood urea had risen from $4.4 \mathrm{mmol} / 1$ on admission to $15.7 \mathrm{mmol} / \mathrm{l}$ ), the dose was not increased; ceftazidime $2 \mathrm{~g}$ every 12 hours was added. On the fourth day, rightsided tonic-clonic fits occurred, he became more hypotensive and died. A postmortem examination was not performed.

Two blood cultures, taken on the day of admission, yielded motile Gram negative " $S$ " shaped bacteria after five days of incubation. They were identified as $C$ jejuni based on the biochemical tests recommended by Karmali and Skirrow. ${ }^{3}$ The isolate was sensitive to gentamicin, chloramphenicol, and erythromycin, but resistant to penicillin and ampicillin.

\section{Discussion}

Although $C$ jejuni infection usually presents with acute enteritis, septicaemic cases without enteritis have been reported. ${ }^{4}$ The present patient died from hepatic encephalopathy caused by severe $C$ jejuni septicaemia, meningitis being excluded by 
a normal cerebrospinal fluid examination. Severe $C$ jejuni infections have been reported in patients with immunodeficiency, ${ }^{5}$ such as HIV infection. ${ }^{6}$ Only one case of $C$ jejuni septicaemia occuring in a post-splenectomy patient has been reported previously, and that patient was also an iron overloaded thalassaemic with chronic liver disease who also had diabetes mellitus. ${ }^{7}$ There appears to be no obvious reason why $C$ jejuni would show a predilection for growth in such patients, unlike Yersinia spp which grows more readily in iron overloaded patients. ${ }^{8}$ Septicaemic shock is thought to occur in severe $C$ jejuni infections because of the bacteria's lipopolysaccharide content, ${ }^{9}$ and perhaps because of the secretion of an enterotoxin. ${ }^{10}$

Thalassaemia is a common indication for splenectomy, and these patients may be immunocompromised in other ways, for example by the effects of multiple blood transfusions, viral infection, iron overload, or diabetes mellitus. In addition, the presence of chronic liver disease and impaired cardiac function in this patient would have impaired his ability to counter the infection and withstand its effects. Our patient was given gentamicin (to which the organism was sensitive) from the time of admission, but he still died owing to a combination of septicaemic shock and hepatic encephalopathy. Although the dose of gentamicin was as recommended ( $5 \mathrm{mg} / \mathrm{kg} /$ day), no loading dose was given and the post-dose serum concentra- tion was subtherapeutic. These factors may also have contributed to the poor clinical response. The possibility of a campylobacter septicaemia should be considered when a splenectomised thalassaemia patient presents with high grade fever, and appropriate high dose antibiotic coverage should be instituted.

1 Anon. Splenectomy-a long-term risk of infection [editorial]. Lancet 1985;ii:928-9.

2 Working Party of the British Committee for Standards in Haematology Clinical Haematology Task Force. Guidelines for the prevention and treatment of infection in patients with an absent or dysfunctional spleen. BMF 1996;312:430-4.

3 Karmali MA, Skirrow MB. Taxonomy of the genus Campylobacter. In: Butzler JP, ed. Campylobacter infection in man and animals. Boca Raton: CRC Press; 1984:1--20.

4 Spelman DW, Davidson N, Buckmaster ND, Spicer WJ, Ryan P. Campylobacter bacteraemia: a report of 10 cases. Med F Aust 1986;145:503-5.

5 Blaser MJ, Perez-Perez G, Smith PF, Patton C, Tenover FC, Lastovica AJ, et al. Extraintestinal Campylobacter jejuni and Campylobacter coli infections: host factors and strain characteristics. F Infect Dis 1986;153:552-9.

6 Perlman DM, Ampel NM, Schifman RB, Cohn DL, Patton $\mathrm{CM}$, Aguirre ML, et al. Persistent Campylobacter jejuni infections in patients infected with human immunodeficiency virus (HIV). Ann Intern Med 1988;108:540-6.

7 Meyrieux V, Monneret G, Lepape A, Chomarat M, Banssillon V. Fatal septic shock with multiple organ failure due to Campylobacter jejuni. Clin Infect Dis 1996;22:183-4.

8 Robins-Browne RN, Robson AR, Koornkof HJ. Generalised infection with Yersinia enterocolitica and the role of iron. Contrib Microbiol Immunol 1979;5:277-82.

9 Mills SD, Aspinall GO, McDonald AG, Raju TS, Kurjanczyk LA, Penner JL. Lipopolysaccharide antigens of Campylobacter jejuni. In: Nachamkin I, Blaser MJ, Tompkins LS, eds. Campylobacter jejuni: Current status and future trends. Washington, DC: American Society for Microbiology; 1992:223-9.

10 Van Der Zwann JC. Toxic shock syndrome caused by Campylobacter intestinalis [letter]. Lancet 1984;i:449.
Department of Microbiology, All India Institute of Medical Sciences, Ansari Nagar, New Delhi-110 029 , India

Correspondence to: Dr Rama Chaudhry.

Accepted for publication 22 January 1997

\title{
Standardisation of polymerase chain reaction for the detection of Salmonella typhi in typhoid fever
}

\author{
Rama Chaudhry, B V Laxmi, Nazima Nisar, Koninika Ray, Dinesh Kumar
}

\begin{abstract}
To improve the diagnosis of Salmonella typhi infection, a polymerase chain reaction (PCR) assay was developed for the amplification of the dH flagellin gene of $S$ typhi. Primers were designed from $\mathrm{dH}$ flagellin gene sequence which will give an amplification product of 486 base pairs. In tests to study the specificity of the assay, no amplification was seen in nonsalmonella strains or salmonella strains with flagellar gene other than "d". Sensitivity tests determined that $28 \mathrm{pg}$ of $S$ typhi target DNA or $3 \times 10^{2}$ target bacteria could be detected by the PCR assay. Subsequently, the PCR technique was used for detection of $S$ typhi in blood or clot cultures from 84 patients clinically suspected of having typhoid fever, and from 20 healthy control subjects. Twenty five of 84 samples from clinically sus-
\end{abstract}

pected cases were positive by PCR; four of which were culture negative. No amplification was seen in samples from patients who were culture positive for organisms other than $S$ typhi or from controls. The time taken for each sample for PCR analysis was less than 48 hours compared with three to five days for blood or clot culture. PCR appeared to be a promising diagnostic test for typhoid fever.

(F Clin Pathol 1997;50:437-439)

Keywords: Salmonella typhi; polymerase chain reaction; typhoid fever

Typhoid fever, a septicaemic disease caused by Salmonella typhi, is a serious health problem in developing countries. ${ }^{12}$ Diagnosis of typhoid fever currently relies on blood culture and Widal's test. Blood cultures are negative in $30-65 \%$ of cases with typhoid fever because of 